\title{
Prevalence of Gs alpha mutations in Korean patients with pituitary adenomas
}

\author{
H J Kim ${ }^{1}$, M S Kim², Y J Park ${ }^{1}$ S W Kim ${ }^{1}$, D J Park ${ }^{1,3}$, \\ K S Park ${ }^{1,4}$, S Y Kim ${ }^{1,3}$, B Y Cho ${ }^{1,3}$, H K Lee ${ }^{1,4}$, H W Jung ${ }^{5}$, \\ D H Han ${ }^{5}$, H S Lee ${ }^{2}$ and J G Chi ${ }^{2}$ \\ ${ }^{1}$ Department of Internal Medicine, College of Medicine, Seoul National University, Seoul, Korea \\ ${ }^{2}$ Department of Pathology, College of Medicine, Seoul National University, Seoul, Korea \\ ${ }^{3}$ Center for Hormone Research, Clinical Research Institute, Seoul National University Hospital, Seoul, Korea \\ ${ }^{4}$ The Institute of Endocrinology, Nutrition and Metabolism, Seoul National University Medical Research Center, Seoul, Korea \\ ${ }^{5}$ Department of Neurosurgery, College of Medicine, Seoul National University, Seoul, Korea \\ (Requests for offprints should be addressed to S Y Kim, Department of Internal Medicine, College of Medicine, Seoul National University, 28 Yongon-Dong, \\ Chongno-Gu, Seoul 110-744, Korea; Email: seongyk@plaza.snu.ac.kr)
}

\begin{abstract}
The reported frequencies of Gs $\alpha$ mutations (gsp mutations) in growth hormone (GH)-secreting pituitary adenomas are variable (ranging from $4 \cdot 4$ to $43 \%$ ), and the presence of these mutations in the other pituitary adenomas is still a matter of controversy. Previous clinical and biochemical analyses of patients with GH-secreting pituitary adenomas and gsp mutations produced conflicting results and did not demonstrate obvious characteristics. Therefore, we investigated the prevalence of gsp mutations in Korean patients with pituitary adenomas and elucidated the characteristics of these patients. Forty-four GHsecreting adenomas, 7 prolactin (PRL)-secreting adenomas and 32 clinically non-functioning adenomas were examined for the presence of point mutations in codon 201 and 227 of the Gs $\alpha$ gene using a nested PCR and direct sequencing of DNA extracted from fresh tissue or paraffinembedded pituitary adenoma samples. Seven of the $44 \mathrm{GH}$-secreting pituitary adenomas had point mutations
\end{abstract}

at codon 201 or 227; of these, five mutations were in codon 201 and two were in codon 227. In patients with gsp mutations, mean tumor size was significantly smaller than in patients without $g s p$ mutations $(15.9 \pm 8.7 \mathrm{~mm} v s$. $24.9 \pm 14.9 \mathrm{~mm}, P<0 \cdot 05)$. Age, sex, basal GH levels, GH response to oral glucose loading, GH response to octreotide and surgical outcome were not different in the two groups. One of the 32 clinically non-functioning pituitary adenomas had a point mutation at codon 201; none of the seven prolactinomas had these mutations. These results show that $g s p$ mutations are not rare in Korean acromegalic patients and mean tumor size is significantly smaller in acromegalic patients with gsp mutations. Our results also confirm the low frequency of gsp mutations in clinically non-functioning pituitary adenomas and the absence of $g s p$ mutations in prolactinoma.

Journal of Endocrinology (2001) 168, 221-226

\section{Introduction}

The mutations of the gene for the $\alpha$-subunit of $G$ protein $(\mathrm{Gs} \alpha)$ have been identified in human growth hormone (GH)-secreting pituitary adenomas (Vallar et al. 1987, Landis et al. 1989, Clementi et al. 1990, Lyons et al. 1990) and clinically non-functioning pituitary adenomas (Tordjiman et al. 1993, Williamson et al. 1994). The Gs $\alpha$ mutations ( $g s p$ mutations) inhibit the guanine triphosphatase activity of Gs $\alpha$. Inhibition of guanine triphosphatase leads to persistent activation of adenylyl cyclase and continually elevated intracellular cAMP levels in pituitary tissue, leading to cellular proliferation, differentiation and hypersecretion. Thus, gsp mutations in pituitary tissues result in hyperfunctioning and non-functioning gland adenomas (Landis et al. 1989, Dhanasekaran et al. 1995). These mutations are detected in either codon 201 in exon 8 (arginine replaced by cysteine, serine or histidine) or codon 227 in exon 9 (glutamine replaced by arginine or leucine) of the Gs $\alpha$ gene.

The reported frequencies of gsp mutations in patients with GH-secreting pituitary adenomas ranged from $4 \cdot 4$ to $43 \%$ of examined cases (Lyons et al. 1990, Hosoi et al. 1993). It is reported that the prevalence of $g s p$ mutations in GH-secreting pituitary adenomas varies by geographic location and the genetic background of the population (Hosoi et al. 1993). In Caucasians, the prevalence of gsp mutations was $27-43 \%$ of GH-secreting pituitary 
adenomas (Lyons et al. 1990, Barlier et al. 1998), but in Japanese, the prevalence of $g s p$ mutations was considerably lower (4-4-9.3\%) (Hosoi et al. 1993, Yoshimoto et al. 1993). By contrast, Yang et al. (1996) reported that mutation of the gsp gene of GH-secreting adenomas in Korean acromegalic patients is as common as that found in Caucasian patients.

Although several investigators have demonstrated the characteristics of $g s p$ mutations in individuals with GHsecreting pituitary adenomas, available published information does not adequately describe the characteristics of such mutations. Some studies have suggested that the gsp-positive tumors are smaller (Landis et al. 1990, Spada et al. 1990, Boggild et al. 1994) and have lower levels of GH (Landis et al. 1990), but these have not been confirmed by other studies (Harris et al. 1992, Adams et al. 1993, Yang et al. 1996). Several results have shown that the GH nadir was significantly lower in $g s p$-positive adenomas during acute octreotide testing (Faglia et al. 1996, Yang et al. 1996). Recently Barlier et al. (1998) reported that gsp-positive tumors should have a better prognosis and that $g s p$ mutation could provide a marker for tumor response to the somatostatin analog.

In addition to $\mathrm{GH}$-secreting pituitary adenomas, gsp mutations have also been reported in clinically nonfunctioning pituitary adenomas (Tordjman et al. 1993, Williamson et al. 1994). These gsp mutations were detected in about $10 \%$ of the clinically non-functioning pituitary adenomas examined, and were located at codons 201 and 227.

In this study, we investigated the prevalence of $g s p$ mutations between codons 184 and 251 in Korean patients with pituitary adenomas and analyzed the characteristics of patients with pituitary adenomas and gsp mutations.

\section{Materials and Methods}

\section{Subjects}

Eighty-three patients with pituitary adenomas who underwent trans-sphenoidal adenomectomy at Seoul National University Hospital from April 1994 to July 1998 were involved in this study. Of these, there were 44 patients with acromegaly, 7 patients with prolactinoma and 32 patients with clinically non-functioning pituitary adenoma. None had previously undergone radiation therapy. Informed consent was obtained from all subjects. Ethical approval was given for the study protocol by the appropriate University authority.

Diagnosis of acromegaly was on the basis of clinical features, a failure to suppress $\mathrm{GH}$ to $<5 \mu \mathrm{g} / 1$ during an oral glucose tolerance test (OGTT) and immunohistochemical staining of the tumors for GH. The duration of disease was estimated by carefully questioning patients and relatives. Prolactinoma was confirmed by elevated serum prolactin (PRL) levels of $>200 \mu \mathrm{g} / 1$ and immunological staining techniques. Diagnosis of clinically non-functioning pituitary adenoma was on the basis of the lack of clinical and laboratory evidence of hormonal hypersecretion.

\section{Hormone assays and light microscopic findings}

In all patients, anterior pituitary functions were evaluated before surgery and re-evaluated post-operatively. Basal pituitary function, and if indicated, dynamic testing of the pituitary-adrenal axis were assessed in all patients. Serum $\mathrm{GH}$, cortisol, thyrotropin, PRL, luteinizing hormone and follicle-stimulating hormone were measured using the appropriate specific radioimmunoassay. The size and extent of each pituitary tumor were evaluated by magnetic resonance imaging and operative findings. Tumor size was measured as maximal diameter. Tumor size and extension were also graded according to Hardy's classification (Hardy \& Vezina 1976). Tissue samples were confirmed as adenoma by histological examination. Hormone secretion was confirmed by immunohistochemistry.

The basal serum GH levels were taken in the early morning after an overnight fast. Serum GH levels were also expressed as serum GH corrected for tumor size (GH/tumor size). Dynamic GH endocrine studies were performed in 25 acromegalic patients on separate days. Blood samples for GH were obtained at 30-min intervals immediately before and over a $2-\mathrm{h}$ period following an oral $75 \mathrm{~g}$ glucose load. After a single $100 \mu \mathrm{g}$ subcutaneous injection of the somatostatin analog, octreotide (Sandostatin; Sandoz, Switzerland), blood samples were obtained at 0,3 , and 4 h to measure serum GH. Nadir GH levels were obtained at any time during an OGTT and after octreotide injection, and the percentage suppression of GH was calculated. Acromegalic patients were considered to be good responders when the percentage suppression of $\mathrm{GH}$ by octreotide was $>80 \%$ of the basal level. Post-operative normalization of basal GH level $(<2 \mu \mathrm{g} / \mathrm{l})$ was defined as a surgical cure.

\section{DNA extraction}

From 83 tumors, 48 fresh tissue samples obtained directly from the operating room were immediately frozen in liquid nitrogen and stored at $-70{ }^{\circ} \mathrm{C}$ until DNA extraction. The remaining 35 tumors were examined from paraffin-embedded tissue obtained from Seoul National University Hospital Department of Pathology. Genomic DNA was extracted from frozen tissue or paraffin embedded tissue by proteinase $\mathrm{K}$ digestion using a QIAamp Tissue kit (Qiagen, Hilden, Germany) according to the manufacturer's protocol. In the case of paraffin-embedded tissue, sections $(5 \mu \mathrm{m})$ were sliced and de-paraffinized with xylene, and DNA extracted according to the manufacturer's protocol. 


\section{Nested PCR}

PCR amplification of the exon 8-10 region of the Gs $\alpha$ gene was performed from human genomic DNA using the following primers: first PCR, 5'-GCG CTG TGA ACA CCC CAC GTG TCT-3' (sense, 1F) and 5'-CGC AGG GGG TGG GCG GTC ACT CCA-3' (antisense, 1R); and second PCR, $5^{\prime}$-GTG ATC AAG CAG GCT GAC TAT GTG-3' (sense, 2F) and 5'-GCT GCT GGC CAC CAC GAA GAT GAT-3' (antisense, 2R).

The first PCR was carried out with $5 \mu$ l of genomic DNA, using Taq polymerase and $0.5 \mu \mathrm{mol} / 1$ of the $1 \mathrm{~F}$ and $1 \mathrm{R}$ primers in a volume of $20 \mu \mathrm{l}$ and a deoxynucleotide concentration of $0.5 \mathrm{mmol} / \mathrm{l}$. The second PCR was performed with primers $2 \mathrm{~F}$ and $2 \mathrm{R}$ and a 1:1000 dilution of the first PCR product as a template. Nested PCR was carried out in a thermal cycler 2400 (Perkin-Elmer/Cetus, Norwalk, CT, USA) as follows: 30 cycles at $95{ }^{\circ} \mathrm{C}$ for $20 \mathrm{~s}$, $50{ }^{\circ} \mathrm{C}$ for $20 \mathrm{~s}$ and $72{ }^{\circ} \mathrm{C}$ for $30 \mathrm{~s}$ for the first PCR; 35 cycles at $95^{\circ} \mathrm{C}$ for $20 \mathrm{~s}, 57^{\circ} \mathrm{C}$ for $30 \mathrm{~s}$ and $72{ }^{\circ} \mathrm{C}$ for $40 \mathrm{~s}$ for the second PCR. Each of the PCRs was preceded by 3 min of denaturation at $95^{\circ} \mathrm{C}$ and followed by $5 \mathrm{~min}$ of chain elongation at $72{ }^{\circ} \mathrm{C}$.

After PCR amplification, the PCR products were analyzed by gel electrophoresis on a $1.6 \%$ ethidium bromide-stained agarose gel and the DNA visualized under short wavelength UV light.

The double-stranded PCR products resulting from this amplification were purified using a Wizard PCR Preps DNA Purification System (Promega, Madison, WI, USA).

\section{Direct sequencing}

The purified double-stranded PCR products were analyzed to determine the sequence of genomic DNA. The primers were the same as those used in the second PCR. DNA sequences of the PCR products were determined by fluorescence-based dideoxy sequencing using Taq polymerase in a thermal cycler, followed by gel electrophoresis, data collection and analysis on an Applied Biosystems model 373A automated sequencer (Applied Biosystems, Foster City, CA, USA).

\section{Statistical analysis}

Results are expressed as means \pm S.D. Data were analyzed by unpaired Student's $t$-test and Fisher's exact test. $P<0 \cdot 05$ was considered statistically significant.

\section{Results}

The Gs $\alpha$ gene, containing codons 201 and 227, was amplified from each sample by nested PCR. Of the 83 pituitary adenomas, all 83 PCR products gave a single distinct band on gel electrophoresis. The purified double-stranded PCR products were then sequenced to determine the point mutations of the Gs $\alpha$ gene. Gsp mutations were detected in 7 of $44 \mathrm{GH}$-secreting pituitary adenomas and 1 of 32 clinically nonfunctioning pituitary adenomas. No mutations were detected in seven prolactinomas.

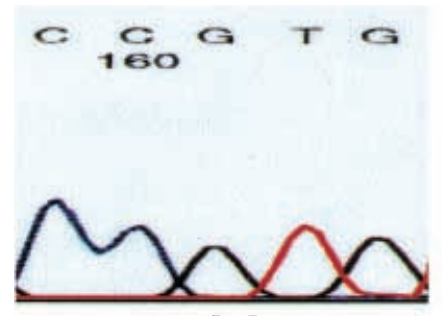

(A) CGT
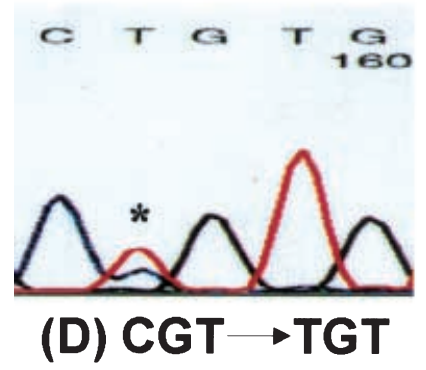

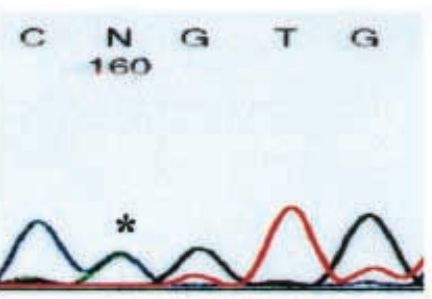

(B) CGT $\rightarrow$ AGT

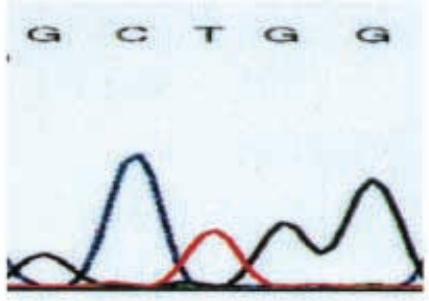

(E) CAG(reverse)
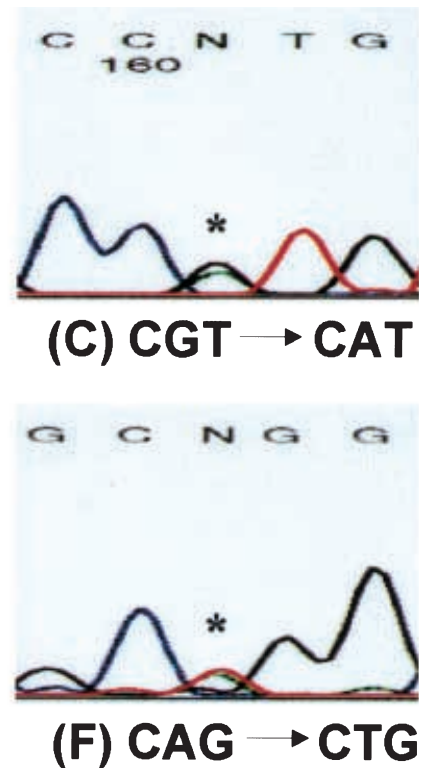

Figure 1 Nucleotide sequence analysis of the Gs $\alpha$ codon 201 and 227 from genomic DNA. (A) Normal codon 201; (B) R201S; (C) R201P; (D) R201C; (E) Normal codon 227; (F) Q227L; *mutated position. 
Table 1 Pre-operative clinical features of acromegalic patients with and without gsp mutations

\begin{tabular}{|c|c|c|}
\hline & $\begin{array}{l}\text { gsp-positive } \\
(n=7)\end{array}$ & $\begin{array}{l}\text { gsp-negative } \\
(n=37)\end{array}$ \\
\hline Age $(y)$ & $41 \cdot 0 \pm 13 \cdot 0$ & $37 \cdot 5 \pm 10 \cdot 8$ \\
\hline $\operatorname{Sex}(M / F)$ & $2 / 5$ & $15 / 22$ \\
\hline BMI $\left(\mathrm{kg} / \mathrm{m}^{2}\right)$ & $25 \cdot 2 \pm 4 \cdot 3$ & $25 \cdot 6 \pm 3 \cdot 5$ \\
\hline Duration of disease $(y)$ & $5 \cdot 4 \pm 4 \cdot 0$ & $10 \cdot 6 \pm 16 \cdot 7$ \\
\hline Basal GH $(\mu \mathrm{g} / \mathrm{l})$ & $72 \cdot 0 \pm 81 \cdot 2$ & $109 \cdot 8 \pm 132 \cdot 4$ \\
\hline Suppression of $\mathrm{GH}$ by octreotide (\%) & $63 \cdot 3 \pm 40 \cdot 5$ & $80 \cdot 0 \pm 23 \cdot 4$ \\
\hline Suppression of GH by glucose (\%) & $21 \cdot 8 \pm 23 \cdot 7$ & $9 \cdot 8 \pm 43 \cdot 0$ \\
\hline Basal PRL $(\mu \mathrm{g} / \mathrm{l})$ & $53 \cdot 9 \pm 97 \cdot 4$ & $49 \cdot 8 \pm 80 \cdot 8$ \\
\hline Tumor size $(\mathrm{mm})$ & $15 \cdot 9 \pm 8 \cdot 7^{*}$ & $25 \cdot 9 \pm 14 \cdot 9$ \\
\hline $\mathrm{GH} /$ size $(\mu \mathrm{g} / \mathrm{l}$ per mm) & $4 \cdot 0 \pm 2 \cdot 6$ & $4 \cdot 1 \pm 4 \cdot 0$ \\
\hline Tumor grade $(1 / 2 / 3 / 4)^{a}$ & $2 / 1 / 2 / 2$ & $3 / 3 / 16 / 15$ \\
\hline
\end{tabular}

*, $P<0.05$ compared to the patients without gsp mutations. $\mathrm{BMI}$, body mass index; PRL, prolactin.

${ }^{a}$ Adenomas were classified by grade on the basis of the classification of Hardy and Vezina: grade 1, microadenoma $(<10 \mathrm{~mm})$; grade 2, tumors $\geq 10 \mathrm{~mm}$ with an enlarged sella; grade 3 , local destruction of the sella floor; grade 4 , diffuse destruction of the sella floor.

Of the seven patients with GH-secreting pituitary adenoma with $g s p$ mutations, five mutations were in codon 201 (arginine was replaced by cysteine in three tumors, by serine in one and by histidine in one), and two were in codon 227 (glutamine was replaced by leucine). A single clinically non-functioning pituitary adenoma was identified as having a gsp mutation in codon 201 (arginine was replaced by cysteine). Figure 1 illustrates examples of the sequencing results of the PCR products.

Table 1 shows the pre-operative clinical characteristics of patients with GH-secreting pituitary adenomas with and without $g s p$ mutations. In patients with $g s p$ mutations, mean tumor size was significantly smaller than in patients without mutations $(15.9 \pm 8.7$ vs. $25.9 \pm 14.9 \mathrm{~mm}, P<$ 0.05). However, basal GH levels, tumor grade and GH/ size were not significantly different between the patients with and without $g s p$ mutations. There were no significant differences in the mean percentage suppressions of $\mathrm{GH}$ by octreotide and glucose between the two groups $(63 \cdot 3 \pm 40 \cdot 5$ vs. $80 \cdot 0 \pm 23 \cdot 4 \%(P>0 \cdot 05), 21 \cdot 8 \pm 23 \cdot 7$ vs. $9 \cdot 8 \pm 43 \cdot 0(P>0 \cdot 05)$, respectively). Three of five patients with gsp mutations and 16 of 20 patients without gsp mutations were good responders. There was no significant difference in age, sex, body mass index, duration of disease and basal PRL levels between the two groups (Table 1). No statistically significant differences were observed in the post-operative serum levels of $\mathrm{GH}$ and insulin-like growth factor-I and the surgical cure rate (Table 2).

\section{Discussion}

In this study, we investigated the prevalence of $g s p$ mutations in Korean patients with pituitary adenomas and
Table 2 Outcome of surgery in patients with and without gsp mutations

\begin{tabular}{|c|c|c|}
\hline & $\begin{array}{l}\text { gsp-positive } \\
(n=7)\end{array}$ & $\begin{array}{l}\text { gsp-negative } \\
(n=37)\end{array}$ \\
\hline \multicolumn{3}{|l|}{ Post-operative } \\
\hline Basal GH ( $\mu \mathrm{g} / \mathrm{l})$ & $25 \cdot 8 \pm 55 \cdot 8$ & $24 \cdot 7 \pm 51 \cdot 5$ \\
\hline IGF-I $(\mu \mathrm{g} / \mathrm{l})$ & $402 \cdot 7 \pm 260 \cdot 4$ & $569 \cdot 1 \pm 415 \cdot 4$ \\
\hline Surgical cure rate $(\%)^{a}$ & $28 \cdot 6$ & $22 \cdot 2$ \\
\hline
\end{tabular}

the clinical characteristics of patients with gsp mutations. Gsp mutations were detected in 7 of $44 \mathrm{GH}$-secreting pituitary adenomas $(15.9 \%)$ and 1 of 32 clinically nonfunctioning pituitary adenomas $(3 \cdot 1 \%)$. There were no $g s p$ mutations in seven prolactinomas.

Several studies have demonstrated the prevalence of gsp mutations in GH-secreting pituitary adenomas. Gsp mutations were present in $27-43 \%$ of somatotroph adenomas in the Caucasian population (Landis et al. 1989, Lyons et al. 1990, Barlier et al. 1998), but the reported frequency of $g s p$ mutations in Japanese acromegalic patients was 4-9\% (Hosoi et al. 1993, Yoshimoto et al. 1993). Thus, race differences have been suggested to be responsible for the different occurrence frequencies of gsp mutations. However, Yang et al. (1996) reported that gsp mutations of $\mathrm{GH}$-secreting adenomas in Korean acromegalic patients were as common as in Caucasian patients. In this study, we found gsp mutations in $15.9 \%$ of the $\mathrm{GH}$-secreting pituitary adenomas we examined; $g s p$ mutations are not rare in Korean GH-secreting pituitary adenoma. Although we cannot provide a clear explanation, it is thought that the different prevalence of gsp mutations in GH-secreting pituitary adenomas is most likely due to the low number of patients examined in the different studies and in the different countries. To further examine the cause of this difference, it will be necessary to investigate the prevalence of gsp mutations in a large number of patients with GH-secreting pituitary adenoma. Gsp mutations in clinically non-functioning pituitary adenomas have been reported in approximately $10 \%$ of tumors examined (Tordjman et al. 1993, Williamson et al. 1994). In this study, we detected $g s p$ mutations in only 1 of 32 clinically non-functioning pituitary adenomas, which indicates that gsp mutations are rare in Korean clinically non-functioning pituitary adenomas.

In this study, of seven GH-secreting pituitary adenomas with gsp mutations, five mutations were in codon 201 (three arginine to cysteine, R201C; one arginine to histidine, R201H; one arginine to serine, R201S) and two were in codon 227 (both glutamine to leucine, Q227L), which are similar to those found previously (Landis et al. 1989, Lyons et al. 1990, Yang et al. 1996). Gsp mutations 
R201C and R201H are frequently observed in human GH-secreting pituitary adenomas (Landis et al. 1989, Lyons et al. 1990, Yang et al. 1996). On the other hand, there have been few reports on the gsp mutations R201S and Q227L in human GH-secreting pituitary adenomas (Clementi et al. 1990, Yang et al. 1996, Yasufuku-Takano et al. 1999). Specifically, R201S is a very rare type of mutation. Only two cases have been reported in previous studies, one case from a Korean study (Yang et al. 1996) and the other case from a recent Japanese study (Yasufuku-Takano et al. 1999). Q227L mutation is also a rare type of mutation. Four cases of Q227L mutation have been reported, three of which were in an Italian study (Clementi et al. 1990) and the other in a Japanese study (Yasufuku-Takano et al. 1999). Of 32 clinically nonfunctioning pituitary adenomas tested, one contained a point mutation in codon 201 (arginine to cysteine, R201C). Williamson et al. (1994) reported that gsp mutations R201C and Q227R were identified in 2 of 22 tumors. In another study of clinically nonfunctioning pituitary adenomas, two tumors were found to have gsp mutations R201C and Q227L (Tordjman et al. 1993).

A number of authors have investigated the relationship between the clinical and biochemical characteristics of patients with $\mathrm{GH}$-secreting pituitary adenomas and $g s p$ mutations, including basal serum GH levels, tumor size and serum GH response to oral glucose or somatostatin analog. Some studies reported that mean tumor size was significantly smaller in tumors with gsp mutations than those in wild-types (Landis et al. 1990, Spada et al. 1990). By contrast, other studies have demonstrated that tumor size was not significantly different (Harris et al. 1992, Adams et al. 1993). In this study, GH-secreting pituitary adenomas with gsp mutations were smaller than those without gsp mutations. No differences in age, sex, BMI, and duration of disease were observed between the two groups. These results are in agreement with those of others (Spada et al. 1990, Harris et al. 1992, Adams et al. 1993, Yang et al. 1996).

Previous studies have indicated that $g s p$ mutations are associated with better octreotide sensitivity. Adams et al. (1995) reported that the absence of gsp oncogenes was often associated with resistance to octreotide in vitro cell culture studies, and data on the relationship between the presence of gsp oncogenes and the sensitivity to somatostatin have been reported (Yang et al. 1996, Barlier et al. 1998). Yang et al. (1996) found that octreotideinduced GH suppression was significantly greater in patients with the gsp oncogene mutation than in those without this mutation. In a long-term study in vivo, it is reported that the percentage inhibition of GH hypersecretion was higher in $g s p$-positive adenomas (Barlier et al. 1998). In contrast to previous reports, which showed that the somatostatin analog, octreotide, powerfully inhibited GH secretion in patients with GH-secreting pituitary adenomas and gsp mutations, there were no significant differences in the mean percentage suppression of $\mathrm{GH}$ by octreotide and the number of good responders to octreotide between the patients with and without gsp mutations. The limitations of our study are that we could not subject all patients with gsp mutations to octreotide testing and that we observed only an acute response to octreotide. The effect of the former was probably minimal in our results, but further study in a large number of patients is required. In regard to the latter, additional studies will be required to determine whether improved long term octreotide responsiveness occurs in patients with gsp mutations in vivo.

In this study, the surgical cure rate was not different in patients with GH-secreting pituitary adenomas with and without gsp mutations. Spada et al. (1990) also reported that the cure rate was similar in acromegalic patients bearing tumors with and without $g s p$ mutations. Recently, it was reported that $g s p$-positive tumors should have a better prognosis because GH hypersecretion was controlled in all patients with gsp mutations, even in those with tumoral tissue remaining after surgery (Barlier et al. 1998). In our study, patients bearing active tumor remnants were not yet treated by the long-term administration of somatostatin agonists after surgery; thus the effect of these agents needs further investigation.

Only one of 32 patients with clinically non-functioning pituitary adenomas had a gsp mutation. Arginine in codon 201 was changed to cysteine (R201C) by mutating codon CGT to TGT, no other mutation was identified at the other codons. The patient was a 32-year-old woman with a pituitary adenoma, which was $45 \mathrm{~mm}$ in diameter, and of Hardy stage 4. She was initially treated by transsphenoidal adenomectomy. After surgery, she was given radiotherapy with a total dose of $5040 \mathrm{cGy}$. Now, she is receiving estrogen- and progesterone-based hormone replacement therapy. We did not examine in detail the characteristics of patients with clinically non-functioning pituitary adenoma and $g s p$ mutation because of the limited number of subjects.

In summary, we have shown that $g s p$ mutations are not rare in Korean acromegalic patients and mean tumor size is significantly smaller in acromegalic patients with $g s p$ mutations. No significant differences were found between patients with GH-secreting pituitary adenomas with and without gsp mutations, in terms of their in vivo acute $\mathrm{GH}$-responses to octreotide-induced GH suppression. We also report the low frequency of $g s p$ mutations in clinically non-functioning pituitary adenomas and the absence of $g s p$ mutations in prolactinoma.

\section{Acknowledgement}

This study was supported by a grant from the Institute of Endocrinology, Nutrition and Metabolism, Seoul National University Medical Research Center 1998. 


\section{References}

Adams EF, Brockmeier S, Friedmann E, Roth M, Buchfelder M \& Fahlbusch R 1993 Clinical and biochemical characteristics of acromegalic patients harboring $g s p$-positive and $g s p$-negative pituitary tumors. Neurosurgery 33 198-203.

Adams EF, Lei T, Buchfelder M, Petersen B \& Fahlbusch R 1995 Biochemical characteristics of human pituitary somatotropinomas with and without gsp mutations: in vitro cell culture studies. Journal of Clinical Endocrinology and Metabolism 80 2077-2081.

Barlier A, Gunz G, Zamora AJ, Morange-Ramos I, Figarella-Branger D, Dufour H, Enjalbert A \& Jaquet P 1998 Pronostic and therapeutic consequences of Gs $\alpha$ mutations in somatotroph adenomas. Journal of Clinical Endocrinology and Metabolism 83 1604-1610.

Boggild MD, Jenkinson S, Pistorello M, Boscaro M, Scanarini M, McTernan P, Perrett CW, Thakker RV \& Clayton RN 1994 Molecular genetic studies of sporadic pituitary tumors. Journal of Clinical Endocrinology and Metabolism 78 387-392.

Clementi E, Malgaretti N, Meldolesi J \& Taramelli R 1990 A new constitutively activating mutation of the Gs protein $\alpha$ subunit-gsp oncogene is found in human pituitary tumours. Oncogene $\mathbf{5}$ 1059-1061.

Dhanasekaran N, Heasley LE \& Johnson GL 1995 G protein-coupled receptor systems involved in cell growth and oncogenesis. Endocrine Reviews 16 259-270.

Faglia G, Arosio M \& Spada A 1996 Gs protein mutations and pituitary tumors: functional correlates and possible therapeutic implications. Metabolism 45 117-119.

Hardy J \& Vezina JL 1976 Transsphenoidal neurosurgery of intracranial neoplasm. Advances in Neurology 15 261-274.

Harris PE, Alexander JM, Bikkal HA, Hsu DW, Hedley-Whyte ET, Klibanski A \& Jameson JL 1992 Glycoprotein hormone $\alpha$-subunit production in somatotroph adenomas with and without Gs $\alpha$ mutations. Journal of Clinical Endocrinology and Metabolism 75 918-923.

Hosoi E, Yokogoshi Y, Hosoi E, Horie H, Sano T, Yamada S \& Saito S 1993 Analysis of the Gs $\alpha$ gene in growth hormone-secreting pituitary adenomas by the polymerase chain reaction-direct sequencing method using paraffin-embedded tissues. Acta Endocrinologica 129 301-306.

Landis CA, Masters SB, Spada A, Pace AM, Bourne HR \& Vallar L 1989 GTPase inhibiting mutations activate the $\alpha$ chain of Gs and stimulate adenylyl cyclase in human pituitary tumours. Nature 340 692-696.

Landis CA, Harsh G, Lyons J, Davis RL, McCormick F \& Bourne HR 1990 Clinical characteristics of acromegalic patients whose pituitary tumors contain mutant Gs protein. Journal of Clinical Endocrinology and Metabolism 71 1416-1420.

Lyons J, Landis CA, Harsh G, Vallar L, Grünewald K, Feichtinger H, Duh Q, Clark OH, Kawasaki E, Bourne HR \& McCormick F 1990 Two G protein oncogenes in human endocrine tumors. Science 249 655-659.

Spada A, Arosio M, Bochicchio D, Bazzoni N, Vallar L, Bassetti M \& Faglia G 1990 Clinical, biochemical, and morphological correlates in patients bearing growth hormone-secreting pituitary tumors with or without constitutively active adenylyl cyclase. Journal of Clinical Endocrinology and Metabolism 71 1421-1426.

Tordjman K, Stern N, Ouaknine G, Yossiphov Y, Razon N, Nordenskjöld M \& Friedman E 1993 Activating mutations of the Gs $\alpha$-gene in non-functioning pituitary tumors. Journal of Clinical Endocrinology and Metabolism 77 765-769.

Vallar L, Spada A \& Giannattasio G 1987 Altered Gs and adenylate cyclase activity in human GH-secreting pituitary adenomas. Nature 330 566-568.

Williamson EA, Daniels M, Foster S, Kelly WF, Kendall-Taylor P \& Harris PE 1994 Gs $\alpha$ and Gi2 $\alpha$ mutations in clinically nonfunctioning pituitary tumours. Clinical Endocrinology 41 815-820.

Yang I, Park S, Ryu M, Woo J, Kim S, Kim J, Kim Y \& Choi Y 1996 Characteristics of $g s p$-positive growth hormone-secreting pituitary tumors in Korean acromegalic patients. European Journal of Endocrinology 134 720-726.

Yasufuku-Takano J, Takano K, Takei T, Fukumoto S, Teramoto A, Takakura K, Yamashita N \& Fujita T 1999 Heterozygous gsp mutation renders ion channels of human somatotroph adenoma cells unresponsive to growth hormone-releasing hormone. Endocrinology $1402018-2026$.

Yoshimoto K, Iwahana H, Fukuda A, Sano T \& Itakura M 1993 Rare mutations of the Gs alpha subunit gene in human endocrine tumors. Cancer 72 1386-1393.

Received 28 June 2000

Accepted 21 September 2000 